\title{
LAS CAUSAS DE LA TRANSPARENCIA FINANCIERA EN ESPAÑA: ¿̇FORTALEZA DEMOCRÁTICA O COYUNTURA CRÍTICA? 1
}

\author{
The causes of financial transparency in Spain: \\ Democratic strenght or critical juncture?
}

\author{
AITOR PÉREZ \\ Real Instituto Elcano \\ aperez@rielcano.org \\ Cómo citar/Citation \\ Pérez, A. (2018) \\ Las causas de la transparencia financiera en España: \\ ¿̇fortaleza democrática o coyuntura crítica? \\ Revista de Estudios Políticos, 179, 231-265. \\ doi: https://doi.org/10.18042/cepc/rep.179.08
}

\section{Resumen}

Este artículo rastrea las causas de la elevada transparencia financiera de España, en línea con los de los países más transparentes del mundo como Finalandia o Dinamarca. Dado que la literatura politológica sobre transparencia, que vincula este concepto al buen funcionamiento de las instituciones democráticas de un país, no ofrece una respuesta a esta pregunta, este artículo aborda un estudio en profundidad del caso español siguiendo una metodología de rastreo de procesos y con el apoyo conceptual del neoinstitucionalismo histórico. La conclusión del artículo es que España optó por una aplicación estricta y acelerada de los estándares internacionales de transparencia internacional en unas circunstancias históricas muy concretas en las que coincidieron, en el ámbito nacional, un momento álgido de la lucha contra ETA y, en el ámbito internacional, la introducción de la financiación del terrorismo en la agenda internacional antiblanqueo como consecuencia de los atentados del $11 \mathrm{~S}$.

1 Este artículo no habría sido posible sin la inestimable y generosa colaboración de las profesoras Margarita Gómez-Reino e Iliana Olivié durante distintas etapas de su investigación previa. Además, sus distintas versiones se han visto mejoradas gracias a los comentarios de los profesores Iván Llamazares, César Colino, Salvador Parrado y Esteban Arribas. 


\section{Palabras clave}

Transparencia; regulación financiera; terrorismo; blanqueo de capitales; neoinstitucionalismo histórico; rastreo de procesos; gobernanza global.

\section{Abstract}

This article traces the antecedents of the high levels of financial transparency in Spain, which are aligned to those of the most transparent countries in the world such as Finland and Denmark. Given that the political science literature on transparency links this concept to democratic deepening and does not offer a response to this question, this article undertakes an in-depth study of the case of Spain. The study follows a process-tracing methodology and is based upon concepts borrowed from historical neo-institutionalism.

The paper concludes that Spain's opting for a strict and accelerated application of the international standards on financial transparency was influenced by very specific historical circumstances. The country was at a critical point in its fight against ETA when the issue of terrorist financing was introduced into the international antimoney laundering agenda as a consequence of the 09/11 attacks.

\section{Keywords}

Transparency; financial regulation; terrorism; money laundering; historical neo-institutionalism; process tracing; global governance. 


\section{SUMARIO}

I. INTRODUCCIÓN. II. ¿̇QUÉ SABEMOS DE LA TRANSPARENCIA FINANCIERA Y DE SUS CAUSAS?: 1. El vínculo teórico entre transparencia y democracia. 2. Los análisis empíricos. 3. La explicación de los activistas de la justicia fiscal. 4. ¿̇Cómo explicar diferencias entre países similares? III. EL CASO ESPAÑOL: 1. La transparencia financiera española al detalle. 2. La hipótesis del terrorismo. 3. Una hipótesis institucionalista-histórica. 4. ¿̇Cómo contrastar empíricamente una coyuntura crítica? 5. La metodología process tracing. IV. ANÁLISIS DE TRANSPARENCIA FINANCIERA ESPAÑOLA: 1. Descomposición de la nota española. 2. Comparación con otros países europeos. 3. El rastreo de las causas: 3.1. 1993, la primera ley contra el blanqueo de capitales. 3.2. 2003, ley contra la financiación del terrorismo. 3.3. 2005, el Órgano Centralizado de Prevención del Consejo General del Notariado de España. 3.4. 2010, nueva ley contra el blanqueo. 3.5. 2014, puesta en marcha de un fichero de titularidades financieras. 3.6. 2015, la rendición de cuentas país a país. 4. ¿̇Fue el $11 \mathrm{~s}$ una coyuntura crítica para España?: 4.1. Cambio político. 4.2. Contingencia. 4.3. Oportunidad. 5. ¿̇Siguen las instituciones españolas una trayectoria dependiente?: 5.1. Inercia. 5.2. Desproporción causa-efecto. 5.3. Costes de establecimiento. V. CONCLUSIONES. Biblografía. AneXos.

\section{INTRODUCCIÓN}

España es el tercer sistema financiero más transparente del mundo según el Índice de Secreto Financiero de Tax Justice Network. Este índice, que sintetiza el cumplimiento de diversos estándares internacionales sobre recogida e intercambio de información financiera por parte de 98 países, indica que España es solo ligeramente menos transparente que Finlandia y Dinamarca, un $20 \%$ más transparente que la media de la UE y un $40 \%$ más que Alemania.

Este dato coincide con la positiva evaluación que España ha recibido del Grupo de Acción Financiera Internacional contra el blanqueo de capitales (GAFI, 2014a). El último informe de revisión entre pares realizado por este organismo señalaba incluso como ejemplos internacionales de buenas prácticas algunos desarrollos institucionales de España.

La literatura politológica no ha elaborado una teoría sobre las causas de la transparencia y tampoco ha prestado atención a las especificidades de la transparencia financiera, pero sí ha establecido un vínculo claro entre la transparencia de un país en general y la fortaleza de sus instituciones democráticas. 
Además, este vínculo ha salido reforzado de numerosos análisis empíricos que comparan indicadores de transparencia de países, regiones y municipios con indicadores de desarrollo democrático.

Desde esta perspectiva, no es de extrañar que en un ranking de transparencia destaquen dos países nórdicos sobre el resto de Europa y del mundo, ya que también ocupan las mejores posiciones en el ranking de Transparencia Internacional sobre corrupción, o en el índice de democracia de The Economist Intelligence Unit. La buena posición de España, por el contrario, sí resulta llamativa porque en estos temas no suele salir tan bien retratada ${ }^{2}$.

Por consiguiente, resulta pertinente analizar en profundidad el caso espańol y explicar su singular desempeño en materia de transparencia financiera. A ello se dedicó un estudio de caso de tipo process tracing, cuyos principales elementos se presentan en este artículo.

En la primera sección de este artículo se repasa brevemente la literatura politológica sobre las causas de la transparencia y se constata que no sirve para explicar el caso español. Seguidamente, en la sección segunda, se propone una explicación alternativa que vincula el desarrollo de la transparencia financiera en España con unas determinadas circunstancias históricas marcadas por la lucha antiterrorista. Esta hipótesis se apoya en los conceptos de coyuntura crítica y trayectoria dependiente, propios del neoinstitucionalismo histórico.

En la tercera sección se presentan los resultados de la investigación como tal: primero, los datos de la transparencia financiera en Espańa; segundo, su análisis en perspectiva comparada; tercero, el rastreo de sus causas; cuarto, la aplicación del marco de análisis y la identificación, por una parte, de una coyuntura crítica y, por otra, de una serie de elementos característicos de la trayectoria dependiente. Finalmente, el artículo se termina con la conclusión sobre el caso español y con una reflexión sobre la pertinencia del enfoque neoinstitucionalista histórico.

\section{II. ¿̇QUÉ SABEMOS DE LA TRANSPARENCIA FINANCIERA Y DE SUS CAUSAS?}

\section{EL VÍNCULO TEÓRICO ENTRE TRANSPARENCIA Y DEMOCRACIA}

La literatura teórica sobre transparencia no se ha dedicado explícitamente a buscar sus causas (Albalate del Sol, 2013; Guillamón et al., 2011), pero las

2 Espańa ocupa el puesto 36, uno de los peores de la UE, en el Índice de percepción de la corrupción, donde Finlandia y Dinamarca ocupan el primer y segundo puesto (TI, 2016). En el Índice de democracia (EIU, 2016), España ocupa el puesto 16 y Finlandia y Dinamarca el $8^{\circ}$ y el $5^{\circ}$. 
vincula claramente al buen funcionamiento de las instituciones democráticas. Esta literatura - que responde a dos enfoques fundamentales, la teoría normativa democrática y la teoría de agencia (Lodge, 2014; Bastida y Benito, 2007)— ve en el acceso a la información sobre la actividad gubernamental una condición necesaria para someterla al control democrático, $\mathrm{o}$, en otros términos, para corregir el comportamiento de un agente mediante sanciones impuestas por su principal.

La transparencia se relaciona por tanto con la rendición de cuentas efectiva y diversos trabajos recurren para ello a la conceptualización de Schedler (1999). Según este autor, la rendición de cuentas (accountability) se descompone en responsabilidad (answerability) y sancionabilidad (enforcement), implicando el primer elemento el derecho de recibir información y la obligación de suministrarla.

Lodge (2014) diferencia cinco tipos de transparencia en el Estado regulador en función de su objeto: la transparencia sobre la adopción de normas, sobre las normas en sí mismas, sobre los actores sujetos a las mismas, sobre el control de su aplicación y sobre la retroalimentación del proceso. El concepto de transparencia financiera implícito en el índice de Tax Justice Network forma parte de la tercera dimensión de la transparencia, la relativa a los actores sujetos a las normas.

Más exactamente, el índice es una síntesis de diversos indicadores de cumplimiento de normas internacionales adoptadas en el ámbito de la ONU y de la OCDE para posibilitar el intercambio de información entre Estados y, por tanto, evitar que los actores sujetos a un conjunto de normas nacionales eludan su cumplimiento ocultando su dinero en los sistemas financieros de otros países. Las normas eludidas pueden ser de tipo tributario o incluso penal, pues el sistema financiero también sirve para ocultar y blanquear las ganancias obtenidas de actividades delictivas.

Con se verá más adelante en este artículo, los indicadores agregados en el índice son normas y acciones de los poderes públicos de un país que aseguran la accesibilidad y el intercambio de información financiera sobre personas físicas y jurídicas, de forma que estas puedan ser vigiladas y perseguidas por evasión fiscal, corrupción, tráficos ilícitos, o cualquier otro incumplimiento de la ley que genere una corriente financiera. Incluso el terrorismo.

\section{LOS ANÁLISIS EMPÍRICOS}

Varios trabajos empíricos han establecido regresiones entre los niveles de transparencia de una serie de países, regiones y municipios, e indicadores de democracia y buen gobierno. En general, la variable dependiente de estos análisis es lo que se conoce como transparencia fiscal, el conjunto de medios legítimos por los que se pueden conocer los objetivos, metas y resultados de los presupuestos y cuentas de los gobiernos (Zucolotto y Teixeira, 2014). Entre las variables independientes contrastadas introducidas en estos análisis 
estarían la existencia de elecciones libres y justas, los contextos electorales reñidos, las bases constitucionales de los tribunales de cuentas o la calidad de las instituciones (Wehner y de Renzio, 2013; Zucolotto y Teixeira, 2014; Tekeng y Sharaf, 2015). Bastida y Benito (2007), sin embargo, demuestran que, en el ámbito de la OCDE, la transparencia fiscal no correlaciona significativamente con índices de democracia aunque sí con índices de percepción de la corrupción.

Cabe señalar, no obstante, que estos mismos estudios han encontrado correlación entre la transparencia fiscal y factores económicos de diversa índole. El turismo influiría negativamente en la transparencia de los municipios españoles y las actividades extractivas tendrían el mismo efecto en los países en desarrollo (Albalate del Sol, 2013; Tekeng y Sharaf, 2015, y Wehner y de Renzio, 2013). Por el contrario, la economía abierta de mercado tendría un efecto positivo en la transparencia de las provincias chinas, y el desarrollo económico en la de los países de la OCDE (Ma, 2012; Bastida y Benito, 2007).

\section{LA EXPLICACIÓN DE LOS ACTIVISTAS DE LA JUSTICIA FISCAL}

Tax Justice Network también recurre al vínculo transparencia-democracia para explicar, por ejemplo, la primera posición en su ranking de Dinamarca, país al que elogia por su tradición en el escrutinio público de los asuntos fiscales (TJN, 2015c). Sin embargo, para esta y otras ONG igualmente activas en la causa de la justicia fiscal, los flujos financieros ilícitos existen porque generan importantes beneficios para el sector de las finanzas internacionales.

Así, democracias tan consolidadas como Suiza o Luxemburgo (TJN, 2015a, 2015b), al concentrar tantos intereses en la industria financiera, no solo no han legislado en favor de la transparencia financiera, sino que incluso lo han hecho en sentido contrario con leyes como las de secreto bancario. Los casos de los denominados paraísos fiscales - que combinan opacidad con baja fiscalidad y fuerte especialización en el sector bancario - han sido caracterizados ampliamente en prensa, pero el índice revela cómo otros países con un perfil aparentemente distinto, como Alemania u Holanda, también tienen niveles muy bajos de transparencia que los informes de (TJN 2015d, 2015e) relacionan con intereses de la banca.

\section{4. ¿̇CÓMO EXPLICAR DIFERENCIAS ENTRE PAÍSES SIMILARES?}

Recurriendo a los dos factores explicativos anteriores - la profundidad democrática y el peso del sector financiero en la economía - se podrían entender muchas de las diferencias que se encuentran entre países próximos, con instituciones y políticas públicas similares, como, por ejemplo, los países europeos que 
se listan en la tabla 1. Sin embargo, el caso español, su distancia respecto a la media europea y su cercanía a los países nórdicos, quedaría sin explicar.

\section{Tabla 1. La transparencia financiera en Europa}

(Transparencia según el ISF 2015: posición de los países europeos en el ranking mundial [98 países] y \%)*

\begin{tabular}{lcc}
\hline & Posición & \% \\
\hline Dinamarca & 1 & 69 \\
\hline Finlandia & 2 & 69 \\
\hline Espańa & 3 & 67 \\
\hline Eslovenia & 4 & 66 \\
\hline Italia & 5 & 65 \\
\hline Rep. Checa & 6 & 65 \\
\hline Hungría & 7 & 64 \\
\hline Suecia & 8 & 64 \\
\hline Polonia & 9 & 64 \\
\hline Grecia & 10 & 64 \\
\hline Noruega & 11 & 62 \\
\hline Portugal & 13 & 61 \\
\hline Irlanda & 14 & 60 \\
\hline Reino Unido & 15 & 59 \\
\hline Bélgica & 16 & 59 \\
\hline Francia & 18 & 57 \\
\hline Estonia & 21 & 56 \\
\hline
\end{tabular}

\begin{tabular}{lcc}
\hline & Posición & \% \\
\hline Letonia & 22 & 55 \\
\hline Islandia & 24 & 54 \\
\hline Países Bajos & 27 & 52 \\
\hline Europa media & - & 52 \\
\hline Malta & 28 & 50 \\
\hline Chipre & 29 & 50 \\
\hline Eslovaquia & 30 & 50 \\
\hline Austria & 34 & 46 \\
\hline Luxemburgo & 38 & 45 \\
\hline Alemania & 39 & 44 \\
\hline Isla de Man & 46 & 36 \\
\hline Gibraltar & 52 & 33 \\
\hline San Marino & 60 & 30 \\
\hline Suiza & 69 & 27 \\
\hline Mónaco & 71 & 26 \\
\hline Liechtenstein & 76 & 24 \\
\hline Andorra & 78 & 23 \\
\hline
\end{tabular}

* El Índice de Secreto Financiero (ISF) es una combinación de dos indicadores: 1) la nota de secreto financiero, una síntesis de quince criterios de transparencia que van desde la prohibición del secreto bancario hasta la participación en acuerdos de cooperación judicial internacional; y 2) una ponderación global, medida del peso del país en la industria global de servicios financieros offshore. En esta tabla, y en todo el artículo, se usa como indicador la primera de las variables, o más exactamente su contrario. O sea, el $67 \%$ de transparencia atribuido a Espańa en este artículo se corresponde con una puntuación del $33 \%$ de secreto financiero en el ISF. Con un 1,09\% de participación en el negocio de los servicios financieros offshore, el país tendría una puntuación final en el ISF de 77,46.

Fuente: elaboración propia a partir del ISF, $2015^{3}$.

3 www.financialsecrecyindex.com 
El neoinstitucionalismo histórico se ha distinguido por explicar por qué países aparentemente similares presentan grandes diferencias en cuestiones como el alcance de sus sistemas de salud, la amplitud de sus políticas de bienestar o en sus estructuras sindicales (Steinmo et al., 1992).

Según esta corriente, «no podemos entender el significado de una variable social particular sin entender cómo llegó hasta ahí, qué trayectoria siguió» (Pierson, 2000). Como se explica a continuación, este artículo no intenta encontrar una explicación general de la transparencia financiera que no deje fuera el caso español, sino que analiza la evolución del caso español a lo largo del tiempo y encuentra una explicación basada en las circunstancias particulares de este país en un momento histórico concreto.

\section{EL CASO ESPAÑOL}

\section{LA TRANSPARENCIA FINANCIERA ESPAÑOLA AL DETALLE}

En la tabla 2 se descompone la nota de España en el índice de referencia al objeto de precisar en qué consiste exactamente su elevada transparencia financiera.

Como se adelantaba en la sección primera, el Índice es una síntesis de indicadores sobre la capacidad de un país de recabar información financiera sobre sus actores económicos y de intercambiarla con otros países. Los indicadores se corresponden con estándares que se han ido definiendo en organismos como el Grupo de Acción Financiera Internacional o el Foro Mundial sobre Intercambio de Información con Fines Tributarios, ambas del ámbito de la OCDE, o en determinados convenios de la ONU contra la corrupción, las drogas, etc.

Por consiguiente, entre los motivos que pueden llevar a los países a recabar e intercambiar este tipo de información está la lucha contra la elusión fiscal de empresas multinacionales (asunto que mueve a las ONG citadas a militar en esta casusa), pero, también, la lucha contra determinados delitos a través de su corriente financiera. En este sentido, cabe destacar que una de las instituciones que más pesa en el Índice es el Grupo de Acción Financiera Internacional, organismo creado en 1991 por impulso del G7 y el apoyo de la OCDE para luchar contra el blanqueo de dinero resultante del narcotráfico. Más adelante, tras el 11 de septiembre de 2001, el mandato de esta institución se amplió a la lucha contra la financiación del terrorismo. 


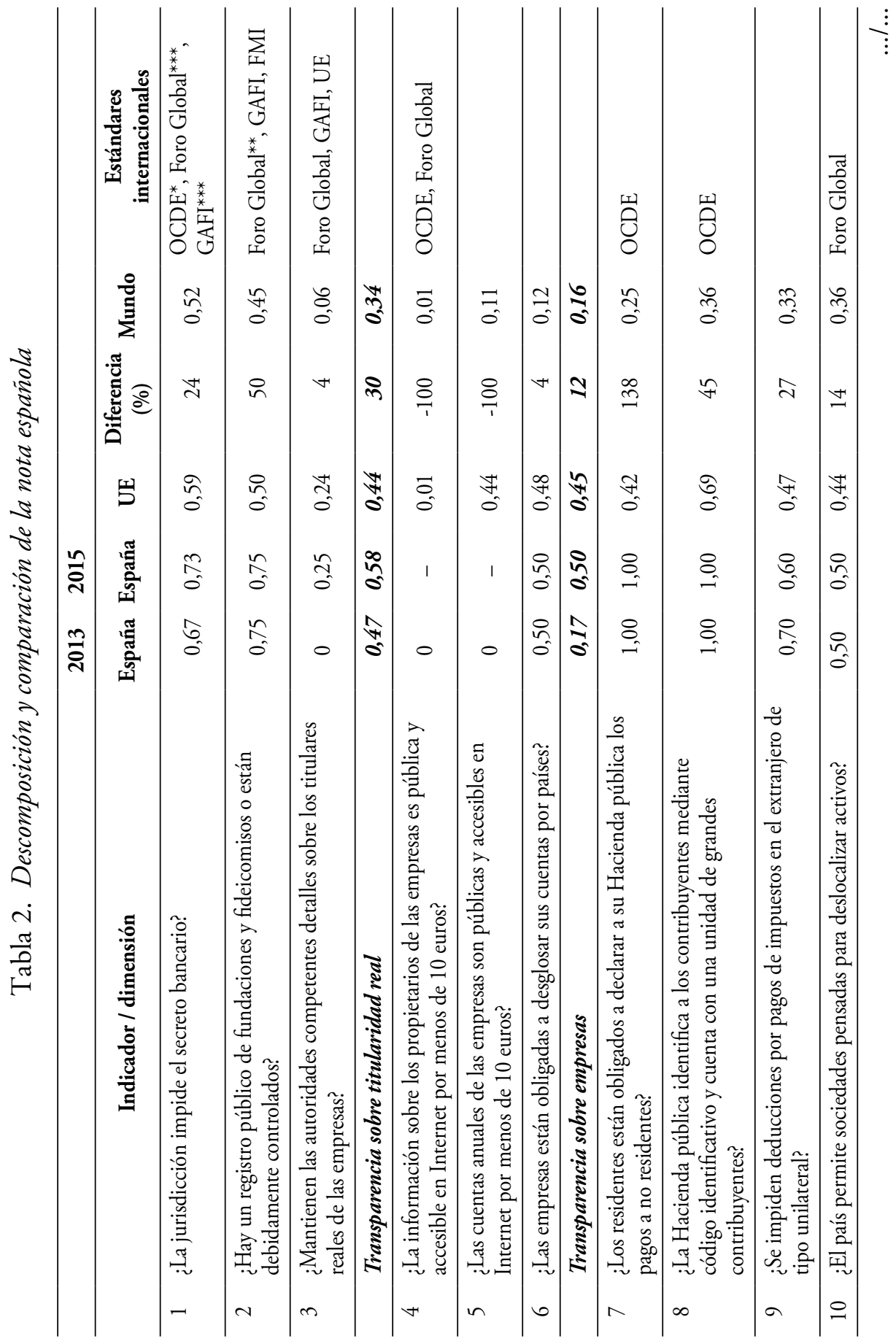




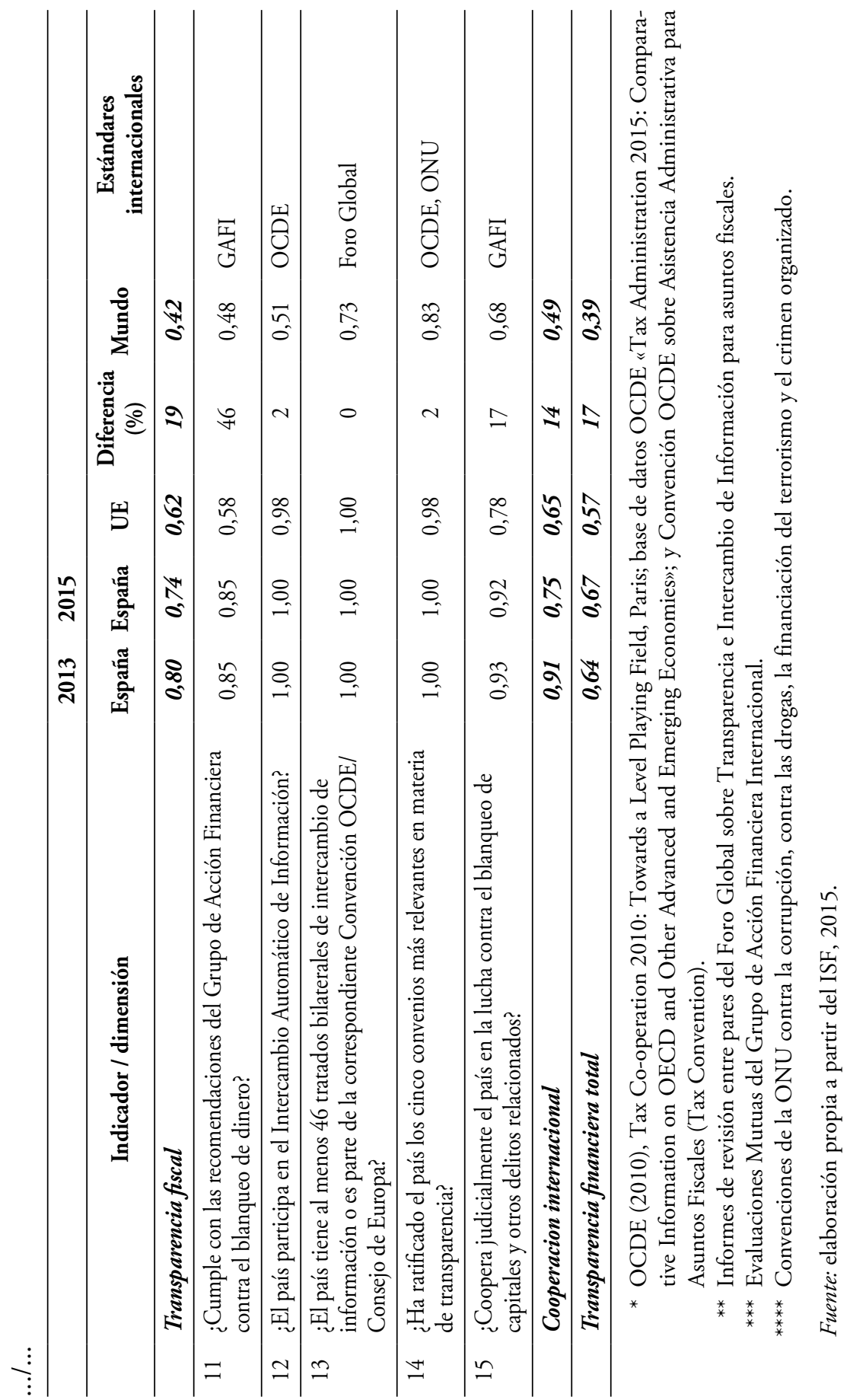




\section{LA HIPÓTESIS DEL TERRORISMO}

Como se demostrará en la sección 3, las instituciones españolas optaron por una aplicación rápida y estricta de los estándares internacionales sobre transparencia financiera precisamente cuando esta agenda confluyó con la de la lucha internacional contra el terrorismo. Esto no era así antes.

Desde 1991 existían directivas europeas basadas en las recomendaciones internacionales contra el blanqueo de capitales. España trasponía estas normas al derecho nacional de forma más o menos mecánica. Sin embargo, cuando en 2001 se organizó la lucha antiterrorista internacional en diversos frentes, incluido el financiero, las estructuras de cooperación internacional contra el blanqueo de capitales se usaron para investigar y perseguir la financiación del terrorismo y, a partir de ahí, el interés de España en esta ámbito de la cooperación internacional creció significativamente.

El país tenía sus propios objetivos antiterroristas en territorio nacional y contaba con buenas experiencias de colaboración internacional en investigaciones sobre la financiación de ETA, por lo que elevó el perfil de su participación en el GAFI y se convirtió en un estricto cumplidor de sus acuerdos. Este perfil diferenciado se mantiene todavía hoy, a pesar de que la situación del terrorismo en España ya no es tan diferente de la de sus países socios.

\section{UNA HIPÓTESIS INSTITUCIONALISTA-HISTÓRICA}

Recurriendo a dos conceptos clave del institucionalismo histórico, la hipótesis anterior se podría reformular en los siguientes términos: la coincidencia de un momento álgido de la lucha antiterrorista española con la introducción de la financiación del terrorismo en la agenda internacional antiblanqueo en 2001 fue una coyuntura crítica para Espańa, en la cual se optó por una aplicación estricta y acelerada de los estándares internacionales de transparencia internacional, que se mantiene hoy en día por un fenómeno de trayectoria dependiente.

Se denomina coyuntura crítica a una situación en la que «las influencias estructurales sobre la acción política (ya sean económicas, culturales, ideológicas u organizativas) están significativamente relajadas durante un periodo relativamente corto de tiempo" (Capoccia y Kelemen, 2007: 343). Se trata de acontecimientos pequeños en relación a la duración y trascendencia de las dinámicas que desencadenan, que contrastan con los factores estructurales de tipo social, económico o cultural, con los que a menudo se explica la política. En palabras de Pierson (2000: 251), este patrón explicativo contrasta fuertemente con los modos dominantes de argumentación en ciencia política, que suele relacionar grandes causas con grandes consecuencias, por lo que se 
podría decir que lo más llamativo de este tipo de explicaciones es la desproporción entre causa y efecto.

Si las coyunturas críticas se han definido como situaciones en las que los actores políticos ven ampliadas sus opciones durante un corto periodo de tiempo, otras dos de sus características definitorias serían la contingencia (los políticos pueden optar por el cambio o no) y la oportunidad (esa posibilidad no se mantiene indefinidamente en el tiempo).

La idea de coyuntura crítica va muy ligada a la de trayectoria dependiente. Este término designa una modalidad de influencia histórica en las instituciones, según la cual «los pasos previos en una determinada dirección inducirían movimientos posteriores en la misma dirección» (Pierson, 2000: 252). En otras palabras, la trayectoria dependiente implica lo que coloquialmente se denomina inercia institucional.

El concepto de trayectoria dependiente procede del ámbito de la economía, donde ha servido para explicar por qué determinadas industrias se concentran en algunas zonas o por qué determinadas soluciones tecnológicas se imponen a otras en el mercado (Krugman, 1992; Arthur, 1994). Estas explicaciones estarían ligadas a la idea de los rendimientos crecientes que se generan al mantener una actividad empresarial una vez que se han afrontado unos costes fijos de establecimiento.

Para Pierson (2000), todos estos factores también pueden explicar por qué una opción política se mantiene y se refuerza en el tiempo: «En contextos de interdependencia social compleja, las nuevas instituciones y políticas son costosas de crear y a menudo generan efecto aprendizaje, efecto coordinación y expectativas adaptativas». Además, considera que, en el ámbito político, el desarrollo de identidades y las asignaciones de poder actúan también como costes de establecimiento que dificultan el cambio de dirección política. En resumen, y simplificando el trabajo de Pierson, se podría decir que una decisión colectiva tenderá a generar rendimientos crecientes, y por tanto, trayectorias dependientes, cuando implique fuertes costes de establecimiento al estilo de los desarrollos tecnológicos. Estos costes de establecimiento se materializarían en acuerdos políticos, aprendizajes individuales, desarrollos organizativos, vínculos entre organizaciones e individuos y asignaciones de poder, y serían propios de contextos sociales complejos.

Los conceptos de coyuntura crítica y trayectoria dependiente a menudo se presentan conjuntamente. La coyuntura no sería crítica, si no tiene consecuencias relevantes, como, por ejemplo, el desencadenamiento de una trayectoria dependiente. Por otra parte, la idea de trayectoria dependiente solo explica la estabilidad pero no el cambio (Kay, 2005), por lo que necesita de un complemento como el concepto de coyuntura crítica para explicar el origen o la modificación de una trayectoria institucional y, por tanto, el cambio político. 
Ambos conceptos se presentan como un patrón explicativo de tipo institucionalista histórico porque ofrecen explicaciones sobre las políticas de un país basadas en las características de sus instituciones, las cuales vendrían marcadas por experiencias vividas en determinadas coyunturas históricas. Otro patrón institucionalista histórico sería, por ejemplo, el que presenta la evolución política como la introducción en un momento histórico determinado de una idea que guía a las instituciones durante un largo periodo de tiempo hasta que una nueva idea viene a remplazarla (Steinmo et al., 1992). Como se verá a continuación, en este caso tuvieron más importancia las circunstancias que las ideas.

A continuación, las características definitorias de la coyuntura crítica y la trayectoria dependiente, en cursiva en los párrafos anteriores, se presentan gráficamente como marco conceptual con el que analizar el caso español en materia de transparencia financiera.

\section{Cuadro 1. ¿Cómo identificar una dinámica de coyuntura crítica y trayectoria dependiente?}

Coyuntura crítica

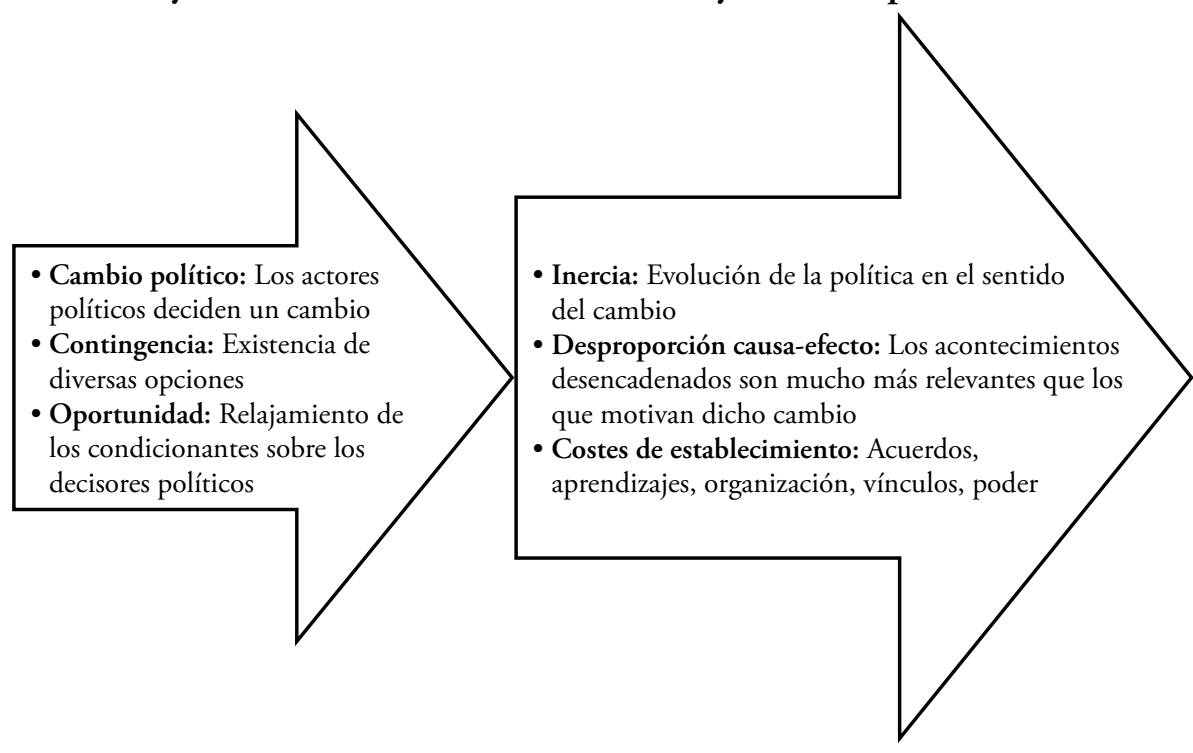

Fuente: elaboración propia.

\section{4. ¿CÓMO CONTRASTAR EMPÍRICAMENTE UNA COYUNTURA CRÍTICA?}

La hipótesis de esta investigación se refiere a España, sus instituciones y las circunstancias históricas que las han rodeado. Por tanto, este estudio sirve 
para explicar el caso español y sus conclusiones no son extrapolables a otros contextos.

Por otra parte, el enfoque teórico adoptado, el institucionalismo histórico, difícilmente puede derivar en estudios de un número grande de casos, pues considera que el cambio político depende de las circunstancias de cada país en un momento concreto. En otras palabras, con esta hipótesis, las decisiones metodológicas son más bien ontológicas ${ }^{4}$.

Desde el enfoque de los politólogos, que vinculan transparencia y democracia, o el de los activistas de la justicia fiscal, que vinculan opacidad y concentración de la industria financiera, tendrían sentido análisis empíricos con una $\mathrm{N}$ más grande. Sin embargo, el enfoque institucionalista histórico, centrado en circunstancias particulares, solo puede contrastarse caso a caso, y por tanto la única manera de que el análisis empírico retroalimente la teoría es mediante la acumulación de evidencias. Por consiguiente, mediante la validación de la hipótesis de esta investigación, en cierta manera se reforzarían los axiomas generales de este enfoque teórico (las instituciones importan, la historia importa) y se debilitarían o matizarían otros axiomas (los actores son racionales, la política varía en cada país en función de sus estructuras económicas y sociales).

\section{LA METODOLOGÍA PROCESS TRACING}

Este estudio de caso ha consistido en identificar los elementos del sistema financiero español que lo hacen tan transparente, indagar en sus bases legales y remontarse al momento de adopción de las mismas para comprender sus motivaciones políticas. Se trata por tanto de un estudio de caso de tipo process tracing o rastreo de procesos, indicado para combinar enfoques positivistas e interpretivistas (Venesson, 2013). Desde una perspectiva positivista, se identifica la presencia o ausencia de las variables relacionadas en la hipótesis, y desde una perspectiva interpretivista, se indaga en las motivaciones para confirmar el vínculo causa-efecto. De esta forma, se realizan atribuciones de causalidad sin necesidad de comparar con otros casos.

Dicho esto, antes de iniciar el rastreo de las causas (sección IV.3.), se realiza una breve comparación del caso estudiado con otros sistemas similares y resultados diferentes, siguiendo los cánones de John Stuart Mill (sección IV.2). Previamente, se desgrana con el apoyo del propio ISF los rasgos diferenciales más relevantes del caso español, cuyas causas o motivaciones deberán identificarse (sección IV.1).

4 Para una reflexión más amplia en este sentido, véase Hall (2003). 
Puesto que detrás de cada una de esas diferencias es posible encontrar una norma de alto rango - leyes y reglamentos adoptados por las Cortes Generales-, es posible también indagar en sus motivaciones por medio de documentos históricos que acompañan a la actividad legislativa: las declaraciones en prensa de políticos, los preámbulos de las propias normas, o el Diario de Sesiones del Congreso 5 .

Otros trabajos de tipo institucionalista-histórico han seguido una estrategia similar. Ellen Immergut (1992), por ejemplo, en el ámbito de las políticas sanitarias, rastreó la estructura formal de las medidas legislativas para examinar las motivaciones e intereses que soportaban cada decisión, los vetos que se evitaban y las alegaciones que se presentan a cada decisión adoptada.

$\mathrm{La}$ investigación se ha nutrido también de entrevistas a funcionarios. $\mathrm{La}$ mayor parte de estas entrevistas fueron previas al análisis documental y, puesto que incluían a la administración europea, belga y española, sirvieron para establecer la comparación inicial entre España y la media europea y formular la hipótesis de esta investigación ${ }^{6}$. La última entrevista fue en paralelo al trabajo documental, en la Dirección General del Tesoro, y sirvió para recomponer la secuencia histórica de las principales medidas de transparencia financiera en España y los pasos seguidos con carácter previo a su adopción ${ }^{7}$.

\section{ANÁLISIS DE LA TRANSPARENCIA FINANCIERA ESPAÑOLA}

\section{DESCOMPOSICIÓN DE LA NOTA ESPAÑOLA}

El ISF se desagrega en cuatro dimensiones, con quince indicadores que remiten casi siempre a fuentes internacionales que promueven y hacen seguimiento de determinadas medidas. Por ejemplo, dentro de la primera de las cuatro dimensiones del índice (titularidad real), el primero de los quince indicadores (secreto bancario) remite a un informe de la OCDE sobre cooperación fiscal, al Foro Global sobre la Transparencia y el Intercambio de Información con Fines

\section{Anexo 2.}

6 Este estudio en profundidad del caso español es continuación de un estudio de casos comparados, más descriptivo y superficial, que sirvió para elaborar un informe del Centro de Desarrollo Global sobre el secreto financiero en Europa desde una perspectiva de desarrollo (Pérez y Olivié, 2014). Los casos analizados en este informe son las instituciones europeas y tres Estados miembros con niveles de transparencia muy distintos según el índice: Luxemburgo, la jurisdicción más opaca de la UE (33\% en el ISF); Bélgica, justo en la media europea (55\%); y España.

7 Anexo 1. 
Fiscales y a los informes de evaluación del GAFI. Estos últimos, a efectos de este indicador concreto, se utilizan para determinar si el país cumple con las recomendaciones 5 y 10 del GAFI que instan a los gobiernos a prohibir a los bancos el uso de cuentas anónimas y a obligarles a custodiar los documentos identificativos de cada cuenta al menos durante cinco años. La nota de España en 2015 (67\% en total) se ha decompuesto en la tabla 2 en las 4 dimensiones y los 15 indicadores y se ha puesto en comparación con las notas medias del mundo y de la UE en ese mismo año, y con la nota del propio país en la edición anterior del índice en 2013.

De dicha tabla se deducen varias informaciones relevantes. En primer lugar, los indicadores que componen el índice se obtienen en un porcentaje muy elevado de elementos de los informes de evaluación del GAFI. España obtiene una diferencia mayor respecto de la UE $(30 \%)$ precisamente en la primera dimensión del índice, donde pesan más los estándares del GAFI, en titularidad real y cooperación internacional. En el indicador específicamente dedicado al GAFI la diferencia es del $48 \%$.

Por otra parte, las deficiencias que recoge la edición 2015 del índice, con datos de años anteriores, podrían haber sido superadas ya. Por ejemplo, el control de la titularidad real de empresas (indicador 3, puntuado en el ISF con 0,25 sobre 1) no solo es un aspecto resuelto según la evaluación de España por parte del GAFI (2014a: 1), sino que representa un «ejemplo de buena práctica» para otros países.

Algo parecido pasaría con la eliminación del secreto bancario, donde el ISF identifica un $25 \%$ de mejora, a pesar de que, desde 2015, el fichero de titularidades bancarias da acceso instantáneo a las autoridades a todos los activos bancarios de un individuo o empresa. En el ámbito fiscal, la rendición de cuentas país a país también ha sido mejorada recientemente mediante un nuevo reglamento del Impuesto de Sociedades (BOE, 2015), que hizo de España el primer país que transponía este aspecto del plan de acción de la OCDE contra la erosión de bases imponibles y el traslado de beneficios.

Cabe ańadir que, de estas tres medidas, las dos primeras tienen escasos o nulos precedentes internacionales a tenor de las puntuaciones del ISF. Por consiguiente, la segunda conclusión que se extrae es que la ventaja de España no solo es alta, sino que podría estar incrementándose. De hecho, comparando el índice de 2015 con el de 2013, se extrae que mientras España sube en transparencia financiera (del 64\% al 67\%), la media mundial baja (del 40\% al 29\%).

En tercer lugar, sobre los aspectos donde España obtiene peor nota, relacionados con información financiera empresarial, cabe destacar que las deficiencias a las que apunta el índice se resumen en el elevado coste para el público de obtener información del Registro Mercantil, lo cual no implica opacidad frente a las autoridades. 


\section{COMPARACIÓN CON OTROS PAÍSES EUROPEOS}

La nota de España (67\%), e incluso la de Dinamarca y Finlandia, en realidad no llega a un $70 \%$ del total de criterios sintetizados en el ISF, los cuales, por otra parte, son en su mayoría criterios acordados libremente por los propios Estados en foros multilaterales. Sin embargo, es una nota relativamente alta: en la UE la nota media está diez puntos por debajo (57\%) y en algunos de sus Estados miembros — Luxemburgo, Austria o Alemania-, la nota ni siquiera llega al $50 \%$.

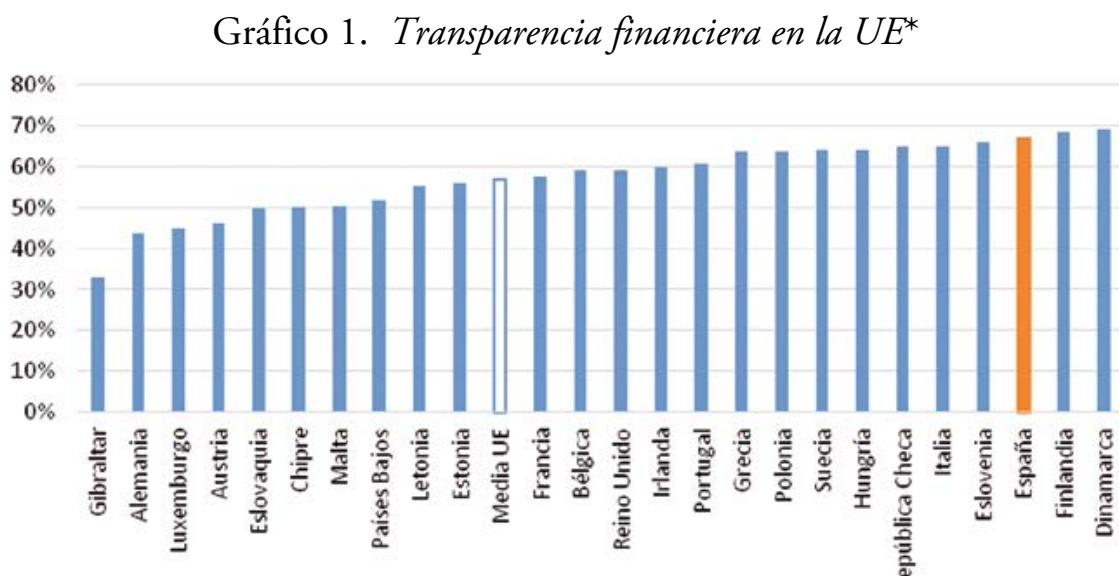

* El gráfico muestra el inverso de la puntuación de secreto financiero, en una escala de 0 a 100, asignada por TJN a países y territorios de la UE. La «media UE» es una elaboración propia, se calcula aritméticamente y no incluye a Croacia, Bulgaria, Rumanía y Lituania por estar ausentes del ranking de TJN. Por el contrario, sí incluye a Gibraltar porque, al tener una jurisdicción distinta del Estado miembro al que pertenece, cuenta con una posición propia en el ranking de TJN.

Fuente: elaboración propia a partir del ISF, 2015.

España destaca sobre la media europea en parte porque esta medida se ve reducida por la baja puntuación de países que se han especializado en atraer capitales internacionales con marcos fiscales y regulatorios laxos, según los editores del índice. No obstante, la nota europea no es simplemente una media de valores altos y bajos. Países tan grandes e importantes como Holanda, Bélgica, Francia y el Reino Unido tienen puntuaciones cercanas a la media europea. Las entrevistas realizadas a funcionarios españoles, por un lado, y a funcionarios belgas, y de las instituciones europeas, por otro, ofrecieron una explicación sobre las diferencias de desempeño dentro de la UE. 
Los informantes espańoles indicaron que, en España, la agenda de la transparencia financiera la marca el GAFI. Bélgica y la propia UE son también miembros del GAFI, pero, según sus funcionarios, la aplicación de sus recomendaciones tiene que salvar algunas dificultades en el ámbito político, e incluso, judicial. Las medidas de transparencia — consistentes en la recopilación y sistematización de datos confidenciales mediante la implicación activa de empresas y profesionales- son contestadas en la UE o en Bélgica por grupos de interés que reclaman el secreto profesional y por grupos políticos que contraponen a la transparencia otros fines y principios como la reducción de cargas administrativas sobre el libre mercado o el derecho a la intimidad.

El propio GAFI ha señalado a España como un país especialmente cumplidor con sus recomendaciones: «tiene leyes y reglamentos actualizados que implantan los estándares revisados del GAFI y cumple con la mayoría de las Recomendaciones» (GAFI, 2014a: 5). Sobre otros países del continente europeo, sus evaluaciones no son tan positivas: sobre Bélgica dice que su marco jurídico «debe ser adaptado a las exigencias del GAFI tal y como fueron revisadas en 2012» (GAFI, 2015: 5); sobre Noruega indica que la «información y el análisis de riesgos relacionados con el blanqueo de dinero son insuficientes y se debe trabajar más en identificar y entender el blanqueo y los delitos con los que se relaciona» (GAFI, 2014b: 5) ${ }^{8}$.

Por consiguiente, la pregunta que motiva este artículo - ¿por qué el sistema financiero español es tan transparente?- se podría reformular así: ¿por qué en España no se cuestiona la aplicación de las recomendaciones del GAFI? En la sección siguiente se responde a esta pregunta presentando cronológicamente las medidas de aplicación de las recomendaciones del GAFI y las circunstancias históricas que las rodearon.

\section{EL RASTREO DE LAS CAUSAS}

\subsection{3, la primera ley contra el blanqueo de capitales}

La primera norma relacionada con los estándares internacionales del GAFI se adoptó en España en 1993 sin recoger mención alguna a esta institución, lo cual hace pensar que este organismo todavía no era una referencia para España. En la exposición de motivos de la Ley se explicaba que esta era una transposición obligatoria de la Directiva europea 91/30B/CEE, la cual sí citaba al GAFI.

8 Las tres frases entrecomilladas se corresponden con el primer párrafo de la sección key findings de los respectivos informes, donde el GAFI expresa la valoración general sobre el cumplimiento de las recomendaciones por parte de cada país. 
La Ley 19/1993 ponía en pie la infraestructura ideada por este organismo internacional y poco a poco implantada con mayor o menor solidez en todos los países OCDE: una red de sujetos (mayoritariamente bancos) obligados a identificar, documentar y comunicar operaciones financieras sospechosas; una unidad de inteligencia financiera, órgano administrativo encargado de recibir esas comunicaciones, sistematizarlas y derivarlas a otras administraciones; $y$ un órgano encargado de asegurar el buen funcionamiento del sistema.

En el caso de España, el liderazgo para la aplicación de esta agenda fue atribuido a la antigua Comisión de Vigilancia de las Infracciones de Control de Cambios, que pasaría a llamarse Comisión de Prevención del Blanqueo de Capitales e Infracciones Monetarias, dependiente de la Secretaría de Estado de Economía. De esta Comisión dependerían dos órganos más, la Secretaría, encargada entre otras cosas de las sanciones a los sujetos obligados, y el Servicio Ejecutivo de la Comisión, el SEPBLANC, integrado en el Banco de España para ejercer las funciones de unidad de inteligencia financiera.

\subsection{3, ley contra la financiación del terrorismo}

Diez años después, las Cortes aprueban una nueva ley que, si bien introduce la figura del bloqueo de capitales como medida administrativa (y no judicial) de prevención de la financiación del terrorismo, vuelve a regular elementos ya regulados en la Ley de 1993. Con el mismo objetivo de perseguir los flujos financieros vinculados a actividades delictivas, repasa la figura del sujeto obligado y sus obligaciones de identificación, documentación y comunicación, crea un órgano más para centralizar las comunicaciones, la Comisión de Vigilancia de Actividades de Financiación del Terrorismo (CVAFT), presidida por el secretario de Estado de Interior.

Años más tarde se resolverían estas duplicidades (la CVAFT quedó derogada sin que se hubiera llegado a reunir), pero lo interesante es entender por qué se incurrió en ellas. A partir de los atentados del 11 de septiembre de 2001, se pusieron en marcha acciones antiterroristas bajo el liderazgo de los Estados Unidos en distintos frentes, incluido el financiero. La financiación del terrorismo se convirtió en un objetivo prioritario de la inteligencia de los países occidentales y se amplió así el foco de la cooperación financiera internacional. En octubre de 2001 el nombre completo del GAFI pasó de Grupo de Acción Financiera Internacional contra el Blanqueo de Capitales a Grupo de Acción Financiera Internacional contra el Blanqueo de Capitales y la Financiación del Terrorismo.

El Gobierno español presidido por José María Aznar se sumó con especial interés a la lucha contra la financiación del terrorismo. Aunque no sufriría un atentado similar al $11 \mathrm{~S}$ hasta tres años después, el 11 de marzo de 2004, 
tenía sus propios objetivos en suelo nacional y un fuerte interés en que existiera un marco internacional para recabar apoyos a sus investigaciones antiterroristas.

Más aún, la experiencia española en la lucha contra ETA demostraba que la cooperación internacional en el ámbito de las finanzas podía dar buenos resultados. Ya en 1986, la Audiencia Nacional, gracias a la cooperación francesa, había conseguido un importante éxito desarticulando el entramado financiero de ETA encubierto bajo la cooperativa Sokoa de Hendaya, Francia.

Cabe añadir que en el momento en que convergen las luchas antiblanqueo y antiterrorista internacionalmente (año 2001), la lucha contra ETA también se intensificaba como consecuencia de su abandono del alto el fuego en 2000. En aquel momento, el Gobierno de Aznar relanzaba la lucha política y policial después de haber silenciado bastante su discurso en el marco de las negociaciones de 1999. La sociedad española también volvía a colocar a la banda terrorista entre sus tres principales preocupaciones según el CIS 9 .

En el ámbito político, el consenso antiterrorista se reforzaba con el Acuerdo por las Libertades y contra el Terrorismo entre el Partido Popular y el Partido Socialista en diciembre de 2001. Este pacto fue iniciativa del entonces líder de la oposición, José Luis Rodríguez Zapatero, y consistía en dejar el terrorismo fuera del debate partidista, reforzando la autonomía del Ejecutivo en la acción antiterrorista, aun cuando contaba con mayoría absoluta.

Todas estas circunstancias quedan reflejadas en el preámbulo de la Ley 12/2003, de 21 de mayo, del cual se extraen a continuación algunas líneas:

El terrorismo constituye una de las mayores agresiones a la paz, a la seguridad y a la estabilidad de las sociedades democráticas. Sucesos como los trágicos atentados del 11 de septiembre de 2001 no han hecho sino evidenciar aún más que ningún ciudadano, ninguna institución, ni ningún Estado se encuentran al margen de esta amenaza. [...] Del mismo modo y en el ámbito nacional, tanto nuestros compromisos internacionales como la desgraciada experiencia española, que sufre la lacra del terrorismo desde hace décadas, hacen necesario completar nuestro ordenamiento jurídico con medidas eficaces en el ámbito de la prevención de esta forma de delincuencia, dentro del respeto a los principios que informan nuestro Estado democrático y de derecho.

9 En la última encuesta del CIS sobre las principales preocupaciones de los españoles antes de la ruptura del alto el fuego de ETA en 1999, solo el $25 \%$ de los encuestados colocaba el asunto «Terrorismo. ETA» entre los tres principales problemas del país. Después de la tregua, este porcentaje sube a niveles del 60 , del 70 e incluso del $80 \%$. 


\subsection{5, el Órgano Centralizado de Prevención del Consejo General del Notariado de España}

Bajo un Gobierno de distinto signo político, el primero de José Luis Rodríguez Zapatero, se creó mediante una Orden Ministerial (BOE, 2005) el Órgano Centralizado de Prevención (OCP) dentro del Consejo General del Notariado. Su función era y es centralizar la información mercantil de todos los notarios del país con el objetivo de identificar operaciones sospechosas de blanqueo de capitales. El OCP conectó al SEPBLANC con una red de informantes estratégicamente colocados dentro del tráfico mercantil, los notarios, y puso en marcha un índice único informatizado para que estos volcaran rutinariamente información procedente de sus actas bajo unos parámetros que permitieran detectar automáticamente operaciones sospechosas.

Como se adelantaba en la sección 3.2, años más tarde, el GAFI (2014) destacaría esta colaboración entre el SEPBLANC y los notarios como una buena práctica internacional. A través de este índice informatizado, el titular real o beneficiario último de una sociedad es identificado y registrado cada vez que dicha sociedad eleva a público un acuerdo. Dado que el Registro Mercantil solo procesa los socios que constituyen una sociedad, pero no sus distintos traspasos de acciones, el índice del notariado se ha convertido en un registro de titulares reales de empresa homologado por el GAFI. Antes del informe del GAFI, esta solución ya había sido reconocida a nivel nacional y europeo ${ }^{10}$.

Este registro no es público y por tanto no cumpliría todos los requisitos del ISF, pero es a día de hoy la mejor solución al problema de la titularidad real y es accesible a través del SEPBLANC a todas las administraciones. Más aún, en 2015, un acuerdo entre el Consejo General del Notariado y la Asociación Española de la Banca, junto con la Confederación Española de Cajas de Ahorros, ha extendido el acceso a esta información a las instituciones financieras.

\subsection{0, nueva ley contra el blanqueo}

A pesar de que España había obtenido una evaluación relativamente buena por parte del GAFI en 2006 con arreglo a las recomendaciones de 2004, una

10 Tal y como se difundió en las notas de prensa y en la revista del Consejo General del Notariado, el Índice fue incluido en el Manual de Buenas Prácticas en la Lucha contra la Criminalidad Financiera del Consejo de la Unión Europea. En Espańa, el director general del Tesoro y de Política Financiera, cuyo departamento ejerce la secretaría de la Comisión de Vigilancia y Prevención del Blanqueo de Capitales, y el ministro de Justicia, Alberto Ruiz-Gallardón, habían reconocido públicamente la contribución del notariado a la fortaleza del sistema antiblanqueo español (véase el anexo 2). 
nueva Directiva europea inspirada por esas recomendaciones debía transponerse a España para, entre otras cosas, ampliar la lista de sujetos a pequeñas empresas y profesionales de la asesoría fiscal o la abogacía, además del notariado. De esta forma, se adopta una nueva Ley que se aprovecha para unificar los regímenes de prevención del blanqueo de capitales y de la financiación del terrorismo, poniendo fin a la dispersión anterior, según la propia norma (BOE, 2014: 2), otro dato destacable de la exposición de motivos es el alineamiento directo de España con las recomendaciones del GAFI y su declaración de intenciones más allá de los estándares europeos:

Debe subrayarse que la Directiva 2005/60/CE o Tercera Directiva, que básicamente incorpora al derecho comunitario las Recomendaciones del GAFI tras su revisión en 2003, se limita a establecer un marco general que ha de ser, no solo transpuesto, sino completado por los Estados miembros, dando lugar a normas nacionales notablemente más extensas y detalladas, lo que supone que la Directiva no establece un marco integral de prevención del blanqueo de capitales y de la financiación del terrorismo que sea susceptible de ser aplicado por los sujetos obligados sin ulteriores especificaciones por parte del legislador nacional. Por otra parte, la Tercera Directiva es una norma de mínimos, como seńala de forma rotunda su artículo 5, que ha de ser reforzada o extendida atendiendo a los concretos riesgos existentes en cada Estado miembro, lo que justifica que la presente Ley contenga, al igual que la vigente Ley 19/1993, de 28 de diciembre, sobre determinadas medidas de prevención del blanqueo de capitales, algunas disposiciones más rigurosas que la Directiva.

Por tanto, el legislador español, consciente de que el papel de las instituciones europeas en este ámbito se limita a armonizar y establecer un mínimo común denominador, decide por voluntad propia elevar en su jurisdicción las exigencias sobre los actores del sistema financiero en aras de la prevención del blanqueo y la financiación del terrorismo. Esto suscitaría en otros países europeos debates políticos sobre el derecho a la intimidad o el exceso de intervencionismo público en la actividad empresarial. Sin embargo, tal y como se explica a continuación, en España no los suscitó.

El Diario de Sesiones del Congreso de los Diputados de 24 de marzo recoge las intervenciones de los distintos grupos de la Comisión de Economía y Hacienda del Congreso (2010) a propósito de esta ley y no refleja ningún debate sustancial. Todos los grupos parlamentarios se muestran a favor de la Ley en todas sus partes y las intervenciones se limitan a comentar no tanto el proyecto de Ley como las enmiendas a algunos de sus detalles.

Solamente cabría destacar la opinión de la portavoz de Convergencia y Unión en contra de la elevación de los periodos obligatorios de custodia de la 
documentación sobre los plazos de la Directiva europea. Esta enmienda no prosperó y sirvió para que otros grupos se manifestaran explícitamente en línea con el Gobierno en el sentido de elevar el nivel de exigencia de la Ley con respecto a la Directiva.

En la misma Comisión sí se había registrado un cierto desacuerdo en torno a este tema un año antes, cuando se rechazó una proposición no de Ley del grupo UPyD (Congreso, 2009) por la que se instaba al Gobierno a transponer la Directiva y cumplir las indicaciones de la evaluación mutua del GAFI. Este grupo parlamentario, especialmente activo en los debates relacionados con la lucha antiterrorista, invocó repetidamente ese argumento cuando llevó a la Comisión de Economía su proposición.

En resumen, el Gobierno español no encontró ningún obstáculo en las Cortes para dar una nueva vuelta de tuerca a las obligaciones impuestas al sector privado en la prevención del blanqueo e incluso había sido instado a hacerlo antes. Esta información coincide con las valoraciones recogidas mediante entrevista en la Dirección General del Tesoro y Política Financiera donde se redactó el proyecto de ley. Sus funcionarios recuerdan que el texto que salió de la Administración solo recibió retoques menores en el legislativo y fue aprobado unánimemente y sin ningún debate relativo al conflicto entre seguridad y libertades civiles.

Fuera del Congreso, las principales cabeceras de prensa no recogieron ninguna opinión de fondo sobre esta legislación y simplemente se limitaron a ofrecer una descripción jurídica del nuevo texto. Una nota de prensa del Consejo del Notariado a propósito de distintos actos informativos organizados en torno a la nueva ley (véase el anexo 3) permite conocer la satisfacción de autoridades en la materia, como el entonces subdirector general del Tesoro, José Manuel Vega:

España es un país líder en materia de prevención de blanqueo de capitales [...]. Hace unos años la prevención del blanqueo era una política muerta, solo estaba en los libros y no se aplicaba. En ocasiones, la simple publicación de leyes en el BOE no es suficiente para poner en marcha políticas de este tipo, necesitan funcionarios y profesionales que las apliquen.

En esta y otras notas de prensa del Notariado se puede ver también el consenso en torno a la nueva ley y su efectiva aplicación entre profesionales y políticos, del Gobierno y de la oposición. También se verifica en estas fuentes que algunos políticos asociaban directamente esta norma a otros acuerdos internacionales en materia de lucha antiterrorista ${ }^{11}$.

11 Como se puede ver en las notas y artículos de prensa referenciados en el anexo 2, tanto el Consejo General del Notariado como el Colegio de Abogados se manifestaron a través de sus 


\subsection{4, puesta en marcha de un fichero de titularidades financieras}

La última pieza clave del sistema de vigilancia financiera en España es un reglamento de 2014 que concreta la Ley de 2010 en algunos aspectos técnicos, y, en particular, en el desarrollo de un fichero de titularidades financieras. En este fichero, las entidades financieras vuelcan mensualmente los datos identificativos de los titulares de cuentas bancarias y sus posiciones financieras de forma que puedan ser consultadas por los cuerpos de seguridad en investigaciones de delitos sin necesidad de esperar al proceso judicial, cuyos plazos permiten a los investigados reaccionar y ocultar sus activos.

En palabras de Gloria Gómez (PSOE), diputada del PSOE, «este fichero fue solicitado por la Fiscalía Especial Antidroga, ya que cada vez que ponían en marcha una operación contra el narcotráfico, tenían que llevar banco por banco una orden judicial» (Notariado, 2010b: 2). Con este fichero, la Fiscalía podrá acceder a los mismos datos a través del SEPBLANC sin necesidad de orden judicial y con total discreción frente a bancos y clientes.

Cabe añadir que esta iniciativa solo tiene antecedentes en Francia, donde está muy vinculada a la inspección fiscal, y en Alemania en parte, donde la idea de cesión y almacenamiento de datos fue remplazada por un sistema de consulta on line de las bases de las entidades financieras debido a reservas sobre tratamiento de datos personales. El preámbulo del reglamento español indica que la Agencia de Protección de Datos no ha puesto objeciones de ese tipo.

\subsection{5, la rendición de cuentas país a país}

También es destacable una reciente medida adoptada para controlar la elusión fiscal de sociedades transnacionales: la obligación de empresas de desglosar sus cuentas por país. Ello permitirá conocer el origen geográfico de las rentas de una empresa transnacional con independencia de cómo las ha distribuido contablemente por sus distintas filiales.

Esta medida, que constituye un indicador del ISF con notas especialmente bajas en todo el mundo, no es una recomendación del GAFI sino de otra iniciativa de la OCDE, el plan BEPS. Curiosamente, España ha sido

representantes a favor de la colaboración con las autoridades en este ámbito. Aparte de notas de prensa de este tipo y publicaciones especializadas, la prensa no recogió comentarios sobre la Ley en el momento de su adopción, y solamente un año después, el diario Expansión publicó dos declaraciones negativas de sendos abogados a título particular en un artículo que, por lo demás, se centraba en describir la sofisticación de la colaboración entre los notarios y la unidad de inteligencia financiera española. 
también el primer país en aplicarla mediante la reforma del reglamento del impuesto de sociedades.

\section{4. ¿̇FUE EL $11 \mathrm{~S}$ UNA COYUNTURA CRÍTICA PARA ESPAÑA?}

Los datos anteriores indican que el pasado de España en relación al terrorismo ha influido en su nivel actual de transparencia financiera, tal y como la entiende el GAFI, y, en buena medida, en el ISF. A continuación, se explica cómo esta secuencia histórica responde a una dinámica de coyuntura crítica y trayectoria dependiente siguiendo las pautas de la sección 2 sobre el marco de análisis (cuadro 1).

\subsection{Cambio político}

La coyuntura crítica es una explicación del cambio político. Por tanto, la aplicación de este concepto a una situación histórica determinada solo es relevante si conlleva cambio político. En este caso, las palabras de Juan Manuel Vega, entonces subdirector general del Tesoro y Política Financiera, citadas en la sección anterior (Notariado, 2010a), claramente indican que sí se produjo ese cambio, ya que hubo un tiempo en que la prevención del blanqueo era una "política muerta, solo estaba en los libros y no se aplicaba» y en el momento de las declaraciones, España era líder en la materia. Por tanto, entre 1993, cuando se promulga la más antigua de las normas antiblanqueo, y 2010, momento de las declaraciones, se produce un cambio ${ }^{12}$.

Por la lectura anterior de los preámbulos de estas leyes, el cambio político al que hace referencia el subdirector del Tesoro en 2010 podría situarse en el momento de redacción y adopción de la Ley 12/2003. Mientas que la Ley de 1993, sobre prevención del blanqueo, según su propia exposición, vino motivada por la obligación de transponer el derecho comunitario, la Ley de 2003 está fuertemente motivada por razones de primer orden de la política nacional e internacional: el terrorismo de ETA y el de Al Qaeda. La Ley de 2010 busca explícitamente la aplicación estricta de los estándares internacionales y declara insuficientes los estándares de la UE.

12 Cabe destacar que estas declaraciones se producen en un evento del Consejo del Notariado, cuyos profesionales habían sido afectados por una orden ministerial en 2008. Este tipo de normas, junto con los reglamentos - a diferencia de las leyes, directivas y recomendaciones, de carácter más general - tienen consecuencias directas y concretas tanto para las prácticas de los sujetos obligados como para las administraciones que las supervisan (véase, en el anexo 2, la ORDEN EHA/114/2008, de 29 de enero). 


\subsection{Contingencia}

La Ley 12/2003 no era algo inevitable. El Gobierno que la redactó y el Congreso que la aprobó pudieron perfectamente no hacerlo. Por un lado, la estructura de inteligencia financiera ya estaba legalmente establecida desde 1993 y las funciones de la nueva Comisión de Vigilancia, que nunca se reunió, las podían ejercer otras instancias con el apoyo del SEPBLANC. Tal vez sí era necesario regular el bloqueo administrativo de fondos con carácter preventivo, pero no era necesario volver a repasar todos los elementos de un sistema de vigilancia financiera.

Por otra parte, como en cualquier país de la UE, Espańa podría haber esperado a la III Directiva para renovar su legislación nacional. Sin embargo, en España sí se adoptó esa Ley, cuya contribución final, además del bloqueo de fondos, fue su extenso preámbulo y la introducción de la narrativa antiterrorista en el mundo de la regulación financiera.

\subsection{Oportunidad}

La Ley 12/2003, tal y como explica su propia exposición de motivos, se adopta como consecuencia de los atentados del 11S, circunstancias muy graves en las que cabe esperar que los ciudadanos den un margen de maniobra mayor a sus Gobiernos y permitan una mayor intromisión pública en la esfera privada individual. En todos los países, los ciudadanos aceptaron que aumentaran los controles personales en aeropuertos, y en algunos países como Estados Unidos se facultó al Gobierno para intervenir las comunicaciones electrónicas y telefónicas.

En España, durante esta coyuntura crítica se (re)habilitó al SEPBLANC para organizar una red de informantes financieros debido a "la desgraciada experiencia española, que sufre la lacra del terrorismo desde hace décadas» (Ley 12/2003, pág. 1). Como se ha explicado anteriormente, ello pudo estar influido también por experiencias de éxito en la persecución del terrorismo por la vía de su financiación.

Todos estos factores pudieron relajar temporalmente los condicionantes de la acción política en el sentido de Capoccia y Kelemen (2007).

\section{5. ¿̇SIGUEN LAS INSTITUCIONES ESPAÑOLAS UNA TRAYECTORIA DEPENDIENTE?}

\subsection{Inercia}

Con posterioridad a la Ley 12/2003, la política española en relación a la información financiera ha seguido evolucionando en el mismo sentido: menos 
obstáculos para el supervisor público, mayores obligaciones para los actores privados y ninguna concesión a la protección de datos personales o al libre mercado.

Siete años después, la Ley 10/2010 de prevención del blanqueo y de la financiación del terrorismo, actualmente en vigor, ha asociado definitivamente la narrativa antiterrorista con las recomendaciones del GAFI. Muchas de estas recomendaciones estaban ya en la legislación española desde 1993, pero fueron reafirmadas durante la coyuntura crítica con la adopción de la Ley 12/2003 y definitivamente clarificadas con la fusión de ambos regímenes jurídicos en 2010. Es entonces cuando por primera vez la legislación española menciona al GAFI desde su creación en 1989, recorriendo el preámbulo de la nueva Ley sus principales hitos hasta llegar a abarcar la financiación del terrorismo y otros temas como la corrupción política.

En 2014 y 2015, la legislación española de transparencia financiera sigue reforzándose con reglamentos como el fichero centralizado de titularidades financieras o el que obliga a las empresas a rendir cuentas país por país. Estas medidas no son propuestas específicas de las unidades de la lucha antiterrorista - tema que, por cierto, ya no preocupa tanto a la sociedad espańola, ni ocupa tanto a los políticos de la primera línea- sino que son propuestas de la Fiscalía Especial Antidroga o de la Agencia Tributaria. En cualquier caso, podrían responder a una cierta inercia de la Administración española en favor de la transparencia financiera.

Esta inercia explicaría también por qué los funcionarios españoles entrevistados carecen de una explicación sobre su elevado desempeño y se remiten a unas recomendaciones internacionales que aplicarían igualmente en países mucho menos transparentes. Ellos mismos no son verdaderamente conscientes de que la aprobación de las normas que redactan por parte del Consejo de Ministros o de las Cortes no tiene por qué ser automática.

\subsection{Desproporción causa-efecto}

El marco conceptual de la coyuntura crítica y la trayectoria dependiente adquiere mayor valor cuando consigue explicar largas secuencias de acontecimientos relevantes con circunstancias cortas de menor importancia. El 11S y el terrorismo de ETA son sucesos de gran importancia política en general, pero en el ámbito de las finanzas son una cuestión menor desde el punto de vista cuantitativo. La economía del narcotráfico, por ejemplo, se ha estimado en un 2,5\% del PIB mundial, y el fraude fiscal en España, en un $20 \%$. Evidentemente, el terrorismo de ETA o incluso el del ISIS mueve recursos financieros infinitamente menores.

Las memorias del SEPBLANC en España, a pesar de todas las motivaciones anteriormente descritas, indican que las sospechas de terrorismo están 
detrás de menos del $5 \%$ de las operaciones de la unidad de inteligencia financiera española, mientras que el narcotráfico está detrás de casi un $10 \%$ de los operaciones y el delito fiscal y la delincuencia organizada distinta del narcotráfico, de un $30 \%$ cada una. Por tanto, este caso se ajusta también a la idea de que sucesos pequeños pueden desencadenar trayectorias dependientes de larga duración e importantes implicaciones.

\section{Gráfico 2. Actividad delictiva subyacente en las comunicaciones al SEPBLANC}

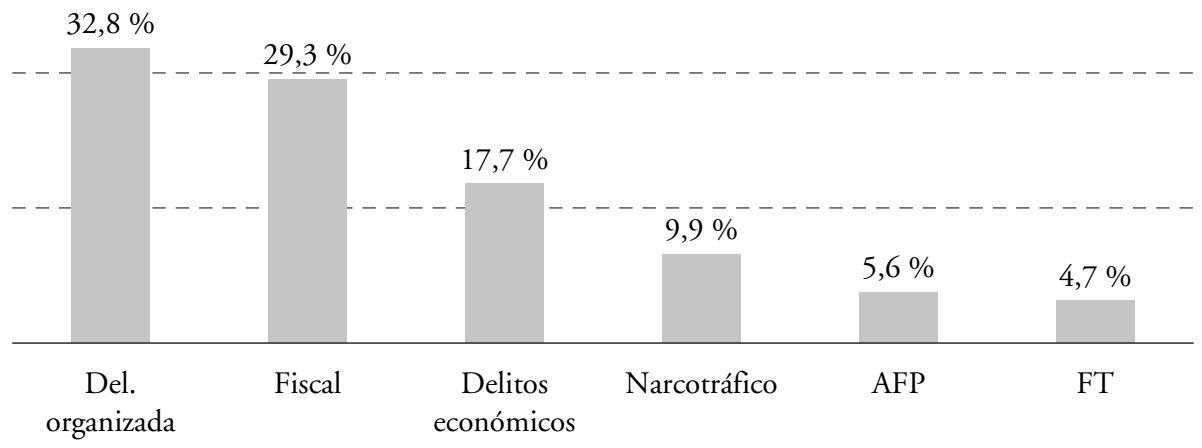

Fuente: SEPBLANC (2013).

\subsection{Costes de establecimiento}

Con las distintas opciones realizadas en los años 2000 en relación a la transparencia financiera, España construyó una infraestructura que perdura en el tiempo y que conlleva unos fuertes costes fijos en el sentido de Pierson (2000). Estos costes dificultarán un cambio de sentido en esta política. Muchos de los tipos de costes fijos que enumera este autor son fácilmente reconocibles en el relato anterior sobre la construcción de la legislación antiblanqueo en España.

Por un lado, las leyes y reglamentos en los que se basa esta política solo pueden ser modificados por nuevos consensos o, al menos, nuevas mayorías parlamentarias, que requerirían negociaciones y deliberaciones. En caso de promoverse un cambio de rumbo en esta política, algunos actores que están viendo sus capacidades reforzadas en este proceso - la Policía, la Guardia Civil, la Agencia Tributaria o la Fiscalía Anticorrupción- posiblemente se opondrían. La Dirección General del Tesoro, ubicada en la cúspide de la estructura 
institucional creada por esta legislación y responsable de la redacción inicial de la misma, probablemente también presentaría alguna resistencia.

Esta política pública no solo ha reforzado el poder de algunas instituciones sino que ha creado otras nuevas: el SEPBLANC, unidad de inteligencia financiera española, los departamentos de cumplimiento legal del sector bancario o el órgano centralizado de prevención del Consejo General del Notariado son organizaciones que ya tienen existencia y vida propia. Algunas de estas nuevas organizaciones podrían incluso generar identidades entre los profesionales que las integran.

El SEPBLANC, por ejemplo, ha ganado fama y prestigio recientemente, gracias a sus investigaciones sobre casos de corrupción de fuerte repercusión mediática y que ya suponen más del $5 \%$ de sus comunicaciones (gráfico 2, columna «AFP»: autoridades y funcionarios públicos). El notariado también, a tenor de sus notas de prensa, está reforzando su identidad de servicio público presentándose como colaboradores del SEPBLANC.

Todos ellos han invertido tiempo y esfuerzo en conocimiento e innovación, como se puede observar en el índice informatizado único del notariado o el fichero centralizado de titularidades financieras. Son medidas que han requerido formación y adaptación pero su manejo es ya una rutina profesional. Incluso los que mayores inversiones han tenido que hacer, que además son actores privados, una vez que se han acostumbrado a dedicar tiempo a indagar en la honradez de sus clientes y han llegado a compartir información con los notarios para tal fin, posiblemente encuentren ventajas en esta obligación, por cuanto que puede reducir sus riesgos de reputación.

Todas estas particularidades del sistema de prevención del blanqueo hacen pensar en los costes de establecimiento (Pierson, 2000). Los funcionarios e incluso algunos profesionales que vigilan y persiguen los flujos financieros ilícitos posiblemente se atrincherarían en su sistema de prevención del blanqueo en el caso poco probable de que un día se forme un consenso distinto en relación al dilema seguridad-libertad y el caso, bastante probable, de que el terrorismo deje de ser un argumento de peso a favor de la transparencia financiera.

Dicho esto, haría falta un horizonte temporal más amplio para visualizar claramente el efecto de estos costes de establecimiento o trincheras en la trayectoria de la regulación financiera.

\section{CONCLUSIONES}

La convergencia de la agenda internacional contra el blanqueo de capitales con la agenda antiterrorista, después del 11S, tuvo especial incidencia en 
España porque se produjo en un momento álgido de la lucha contra ETA. Justo después de su regreso a las armas en 2000, con el nefasto resultado de 23 muertos y 102 heridos solo en ese año. Ese momento sería lo que los neoinstitucionalistas históricos denominan coyuntura crítica.

La retórica del preámbulo de la Ley 12/2003 sobre la lacra terrorista así lo indica. De hecho, esta ley podría considerarse una sobreactuación del Gobierno que no tuvo grandes consecuencias prácticas pero que consiguió introducir con fuerza la relación entre lucha antiterrorista y transparencia financiera, elevando la prioridad política de esta última. A partir de ese momento, en España se optó por el estricto cumplimiento de los estándares internacionales en materia de transparencia financiera y se han ido realizando progresos que no se encuentran en países similares comprometidos con los mismos estándares internacionales. Por ejemplo, el índice informatizado único del notariado o el fichero centralizado de titularidades financieras.

Los últimos progresos en esta materia se han realizado cuando la excepcionalidad espańola en materia de terrorismo ya ha desaparecido y cuando ha quedado demostrado que el objetivo de esta política en el día a día es más bien el crimen organizado, el delito fiscal o incluso la corrupción política. Sin embargo, la perspectiva histórica es todavía algo corta para determinar si las instituciones españolas actúan bajo la influencia de una trayectoria dependiente. Lo que sí resulta evidente es que la Administración española ha incurrido en los costes de establecimiento que según Pierson (2000) explican las trayectorias dependientes en política. A saber, acuerdos políticos de difícil revocación, inversiones en conocimiento, desarrollos organizativos, vínculos entre individuos y organizaciones, y asignaciones de poder.

Este estudio sobre la singularidad del caso español no permite extraer conclusiones generales sobre las causas de la transparencia financiera, pero sí invita a algunas reflexiones sobre las instituciones en general, más allá del caso español y del ámbito de la regulación financiera. Con el levantamiento de un caso más de coyuntura crítica y trayectoria dependiente, se refuerza la idea general de que la historia puede pesar mucho en el comportamiento de las instituciones y, por tanto, en los resultados de las políticas. Por su propia ontología, un enfoque teórico como el neoinstitucionalismo histórico no favorece el uso de métodos cuantitativos (Hall, 2003), por lo que este estudio puede considerarse parte de un ejercicio más amplio de contraste empírico basado en la acumulación de evidencias caso a caso.

\section{Bibliografía}

Albalate del Sol, D. (2013). The Institutional, Economic and Social Determinants of Local Government Transparency. Journal of Economic Policy Reform 16 (1): 90-107. 
Arthur, B. (1994). Increasing Returns and Path Dependence in the Economy. Ann Arbor: University of Michigan Press. Disponible en: https://doi.org/10.3998/mpub.10029.

Bastida, F. y Benito, F. (2007). Central Government Budget Practices and Transparency: An International Comparison. Public Administration, 85 (3), 667-716.

Capoccia, G. y Kelemen, R. D. (2007). The Study of Critical Junctures. Theory, Narrative, and Counterfactuals in Historical Institutionalism. World Politics, 59, 341-369. Disponible en: https://doi.org/10.1017/S0043887100020852.

Cobham, A. (2012). Tax Havens and Illicit Flows. En P. Reuter (ed.). Draining Development? Controlling Flows of Illicit Funds from Developing Countries? The World Bank.

Guillamón, M.D., Bastida, F. y Benito, B. (2011). The Determinants of Local Government's Financial Transparency. Local Government Studies, 37 (4), 391-406.

Hall, P. (1989). The Political Power of Economic Ideas. Princeton University Press.

(2003). Aligning Ontology and Methodology in Comparative Research. En J. Mahoney y D. Rueschemeyer. Comparative Historical Analysis in the Social Sciences. Cambridge, New York: Cambridge University Press. Disponible en: https://doi.org/10.1017/ CBO9780511803963.012.

Immergut, E. (1992). Health politics. Interests and Institutions in Western Politics. Cambridge, New York: Cambridge University Press.

- y Anderson, K. (2008). Historical Institutionalism and West European Politics. West European Politics, 31 (1-2), 345-369. Disponible en: https://doi.org/10.1080/ 01402380701835165.

Kar, D. y LeBlanc, B. (2013). Illicit Financial Flows from Developing Countries: 2002-2011. Global Financial Integrity.

Kay, A. (2005). A critique of the use of path dependency in policy studies. Public Administration, 83 (3), 553-572. Disponible en: https://doi.org/10.1111/j.0033-3298.2005.00462.x.

Krugman, P. (1992). Geografía y comercio. Barcelona: Bosch Editores.

Lodge, M. (2004). Accountability and transparency in regulation: critiques, doctrines and instruments. En J. Jacint y D. Levi-Faur (eds.). Politics of Regulation. (pp. 124-144). Cheltenham: Edward Elgar Publishing.

Ma, L. (2011). What Drives Fiscal Transparency? Evidence from Provincial Governments in China. 1st Global Conference on Transparency Research, Rutgers University-Newark, May 19-20, 2011. Disponible en: https://papers.ssrn.com/sol3/papers.cfm?abstract_id=1807767

Pérez, A. y Olivié, I. (2015). Illicit Financial Flows: Policy Responses in Europe and Implications for Developing Countries.

Pierson, Paul. (2000). Increasing Returns, Path Dependence, and the Study of Politics. The American Political Science Review 94 (2): 251-67.

Schedler, A. (1999). Conceptualizing Accountability. The Self-Restraining State: Power and Accountability in New Democracies, 13-28.

Schneider, F. (2013). The Shadow Economy in Europe, 2013. AT Kearny and VISA Europe.

Steinmo, S., Thelen, K. y Longstreth, F. (1992). Structuring Politics: Historical Institutionalism in Comparative Analysis. Cambridge: Cambridge University Press. Disponible en: https://doi.org/10.1017/CBO9780511528125. 
Tekeng, Y. M. T. y Sharaf, M. F. (2015). Fiscal Transparency, Measurement and Determinants: Evidence from 27 Developing Countries. Journal of Economics and Political Economy, 2 (1), 69-91.

Venesson, P. (2013). Estudios de caso y seguimiento de procesos: teorías y prácticas. En D. Della Porta y M. Keating (eds.). Enfoques y metodologias en las ciencias sociales. Una perspectiva pluralista (pp. 237-254). Madrid: Akal.

Wehner, J. y de Renzio, P. (2013). Citizens, Legislators, and Executive Disclosure: The Political Determinants of Fiscal Transparency. World Development, 41 (1), 96-108. Disponible en: http://doi.org/10.1016/j.worlddev.2012.06.005.

Zuccolotto, R. y Teixeira, M. C. (2014). Budgetary Transparency and Democracy : The Effectiveness of Control Institutions. International Business Research, 7 (6), 83-96. Disponible en: http://doi.org/10.5539/ibr.v7n6p83. 


\section{ANEXOS}

Anexo 1. Entrevistas realizadas

\begin{tabular}{|c|c|c|c|}
\hline Nombre & Cargo & Institución & País \\
\hline Andrés Pérez & Comisario & $\begin{array}{l}\text { Centro de Inteligencia } \\
\text { contra el Terrorismo y el } \\
\text { Crimen Organizado }\end{array}$ & España \\
\hline Raquel Cabeza & $\begin{array}{l}\text { Subdirectora general de } \\
\text { Inspección y Control } \\
\text { de Movimientos de } \\
\text { Capitales }\end{array}$ & $\begin{array}{l}\text { Secretaría General } \\
\text { del Tesoro y Política } \\
\text { Financiera }\end{array}$ & España \\
\hline $\begin{array}{l}\text { Juna Antonio } \\
\text { Aliaga }\end{array}$ & Vocal asesor & $\begin{array}{l}\text { Secretaría General } \\
\text { del Tesoro y Política } \\
\text { Financiera }\end{array}$ & España \\
\hline $\begin{array}{l}\text { Marga García- } \\
\text { Valdecasas }\end{array}$ & Inspectora-jefe & $\begin{array}{l}\text { Agencia Española } \\
\text { de Administración } \\
\text { Tributaria }\end{array}$ & España \\
\hline $\begin{array}{l}\text { Isabel Ramos } \\
\text { Talma }\end{array}$ & $\begin{array}{l}\text { Directora de Área } \\
\text { de Información y } \\
\text { Programas Especiales }\end{array}$ & $\begin{array}{l}\text { Fundación } \\
\text { Internacional y para } \\
\text { Iberoamérica de } \\
\text { Administración y } \\
\text { Políticas Públicas }\end{array}$ & España \\
\hline Johan Denolf & $\begin{array}{l}\text { Commissaire } \\
\text { divisionnaire }\end{array}$ & $\begin{array}{l}\text { Cellule de Traitement des } \\
\text { Informations Financières }\end{array}$ & Bélgica \\
\hline Noel Colpin & $\begin{array}{l}\text { Administrateur Générale } \\
\text { des Douanes }\end{array}$ & Ministère des Finances & Bélgica \\
\hline Patrick Sere & $\begin{array}{l}\text { Directeur du Centre } \\
\text { Anti-Fraude }\end{array}$ & Ministère des Finances & Bélgica \\
\hline Tom Jansen & Ex Chef de cabinet & Ministère des Finances & Bélgica \\
\hline Monika Maglione & $\begin{array}{l}\text { Unidad A1. Dirección } \\
\text { General de Interior }\end{array}$ & Comisión Europea & UE \\
\hline Darjan Darigevic & $\begin{array}{l}\text { Dirección General de } \\
\text { Impuestos y Aduanas }\end{array}$ & Comisión Europea & UE \\
\hline David Schwander & $\begin{array}{l}\text { Dirección General del } \\
\text { Mercado }\end{array}$ & Comisión Europea & UE \\
\hline
\end{tabular}




\section{Anexo 2. Documentación analizada}

ABC (1986). Histórica acción de la Policía francesa contra el aparato de finanzas de ETA. 6-111986. Disponible en: https://goo.gl/D3Vffk.

- (2003). Garzón bloquea las cuentas de familiares del presunto miembro del entramado financiero de ETA en México Jon Artola. 24-7-2003. Disponible en: https:/goo.gl/ 17 som 1 .

BOE (2014). Real Decreto 304/2014, de 5 de mayo, por el que se aprueba el Reglamento de la Ley 10/2010, de 28 de abril, de prevención del blanqueo de capitales y de la financiación del terrorismo. Disponible en: https://goo.gl/JKiVgR.

- (2015). Real Decreto 634/2015, de 10 de julio, por el que se aprueba el Reglamento del Impuesto sobre Sociedades. Disponible en: https://goo.gl/NmJfNk.

CIS (2015). Tres problemas principales que existen actualmente en España. Disponible en: https://goo.gl/DzZKA.

Congreso (2009). Diario de Sesiones del Congreso de los Diputados, IX Legislatura, núm. 213, Comisión de Economía y Hacienda de 10/03/2009. Disponible en: https://goo.gl/KgyNjp.

(2010). Diario de Sesiones del Congreso de los Diputados, IX Legislatura, núm. 503, Comisión de Economía y Hacienda de 24/03/2010. Disponible en: https://goo.gl/ SsV8os.

EIU (2016). Democracy Index 2016, The Economist Intelligence Unit. Disponible en: https:// infographics.economist.com/2017/DemocracyIndex/

El Mundo (2002). El juez Baltasar Garzón congela los fondos de Batasuna. Pide lo mismo a Francia. 5-7-2002. Disponible en: https://goo.gl/19VvL7.

El País (1992). El éxito comenzó en Bidart. 1-7-1992. Disponible en: https://goo.gl/nZQ4P8.

Expansión (2011). Los notarios españoles como modelo para atajar el blanqueo. 13-1-2011. Disponible en: https://goo.gl/2QMeJK.

GAFI/FATF (2012). International Standards on Combating Money Laundering and the Financing of Terrorism \& Proliferation. Disponible en: https://goo.gl/erVJd.

- (2014a). Anti-money laundering and counter-terrorist financing measures - Spain, Fourth, Round Mutual Evaluation Report, FATF. Disponible en: https://goo.gl/gFTJmf.

- (2014b). Anti-money laundering and counter-terrorist financing measures - Norway, Fourth Round Mutual Evaluation Report, FATF. Disponible en: https://goo.gl/ryJSKU. (2015). Anti-money laundering and counter-terrorist financing measures -Belgium, Fourth Round Mutual Evaluation Report, FATF. Disponible en: https://goo.gl/vx6Dg5.

Notariado (2010a). España es un país líder en materia de prevención de blanqueo de capitales. Nota de prensa del Colegio General del Notariado. 12-11-2010. Disponible en: https:// goo.gl/gCeZ78.

- (2010b). Nos gustaría que el modelo de colaboración de los notarios en la prevención del blanqueo de capitales, único a nivel internacional, se extendiera a otras profesiones. Nota de prensa del Colegio General del Notariado. 13-7-2010. Disponible en: https://goo.gl/ia888r.

- (2012). El Notariado es la profesión que más contribuye a la lucha contra el blanqueo de capitales. 24-9-2012. Disponible en: https://goo.gl/X3DapS.

- (2014). El Consejo de la UE reconoce al Notariado por sus buenas prácticas. Disponible en: https://goo.gl/voKmVD. 
OCDE (2010). Tax Co-operation 2010: Towards a Level Playing Field - Assessment by the Global Forum on Transparency and Exchange of Information. Disponible en: https://goo.gl/ BeYNam.

- (2014). Better Policies for Development 2014: Policy Coherence and Illicit Financial Flows. Disponible en: http://dx.doi.org/10.1787/9789264210325-en.

ONU (2015). Outcome document of the Third International Conference on Financing for Development: Addis Ababa Action Agenda, July 15 th 2015. Disponible en: https://goo.gl/ pMJZXW.

SEPBLANC (2013). Memoria Anual 2013. Servicio Ejecutivo de la Comisión de Prevención del Blanqueo de Capitales e Infracciones Monetarias. Disponible en: https://goo.gl/ FoMnuc.

TI (2016). Corruption Perceptions Index 2016, Transparency International. Disponible en : https://www.transparency.org/news/feature/corruption_perceptions_index_2016

TJN (2015a). Narrative Report on Luxembourg, Financial Secrecy Index 2015, Tax Justice Network. Disponible en: https://goo.gl/YM22se.

- (2015b). Narrative Report on Switzerland, Financial Secrecy Index 2015, Tax Justice Network. Disponible en: https://goo.gl/jvEAYH.

- (2015c). Narrative Report on Luxembourg, Financial Secrecy Index 2015, Tax Justice Network. Disponible en: https://goo.gl/GurV6U.

- (2015d). Narrative Report on Germany, Financial Secrecy Index 2015, Tax Justice Network. Disponible en: https://goo.gl/YM22se.

- (2015e). Narrative Report on the Netherlands, Financial Secrecy Index 2015, Tax Justice Network. Disponible en: https://goo.gl/94fp7i.

UNODC (2011). Estimating Illicit Financial Flows from Drug Trafficking and other Transnational Organized Crimes. United Nations Office on Drugs and Crime. 